\title{
Knowledge, Attitude, and Satisfaction of Patients towards Subcutaneous Port
}

\author{
Mahnaz Abavisani ${ }^{1}$, Zakiyeh Amini², Hosnieh Raoufian³ ${ }^{3}$ Akram Gazerani ${ }^{4}$ \\ ${ }^{1}$ Department of Nursing, Neyshabur University of Medical Sciences, Neyshabur, Iran. ${ }^{2}$ Department of Nursing, \\ Faculty of Nursing, North Khorasan University of Medical Sciences, Bojnurd, Iran. ${ }^{3}$ Department of Master of \\ Operating Room, Faculty Member, North Khorasan University of Medical Sciences, Bojnurd, Iran. ${ }^{4}$ Department \\ of Operating Room and Anaesthesia, Neyshabur University of Medical Sciences, Neyshabur, Iran.
}

\section{ABSTRACT}

\section{BACKGROUND}

Venous access is crucial in patients who need repeated infusions. Infusion of medication through subcutaneous ports has been recognized as a valid method for repeated long-term infusions and has many advantages over other methods. The aim of the present study was to investigate the knowledge, attitude, and satisfaction of patients with subcutaneous port.

\section{METHODS}

In this cross-sectional study, convenient purposeful sampling method was used to select patients with subcutaneous port $(n=65)$ who were admitted to teaching hospitals of the city of Mashhad, Iran. The instruments used in the present study included questionnaires on knowledge, attitudes, and satisfaction of patients with subcutaneous port, which were completed by patients, or the researcher in case the patient is unable to do so. Data analysis was then carried out using descriptive statistics.

\section{RESULTS}

The results of the present study showed that $46.6 \%$ of patients $(n=26)$ were generally satisfied with port placement and $41.9 \%$ considered port placement as a good alternative to vein finding method. A total of $40.3 \%$ of patients $(n=25)$ had low anxiety about complications of port placement and reported pain as the most common complication. Furthermore, a total of $35.7 \%$ of patients had sufficient knowledge of the reason of port placement, $31.7 \%$ of the procedure, and $40.5 \%$ of the associated complications.

\section{CONCLUSIONS}

Results of the present study provide necessary information regarding port placement perception and knowledge among patients. The results are effective in recognizing perception and knowledge of patients with subcutaneous port and can thus be used to plan patient education and reduce patients' problems.

\section{KEY WORDS}

Subcutaneous Port, Perception, Knowledge, Patient

\author{
Corresponding Author: \\ Akram Gazerani, \\ Department of Operating and Anaesthesia, \\ Neyshabur University of Medical Sciences, \\ Neyshabur, Iran. \\ E-mail:gazerania1@nums.ac.ir
}

\section{DOI: $10.14260 /$ jemds/2020/467}

Financial or Other Competing Interests: None.

How to Cite This Article:

Abavisani M, Amini Z, Raoufian H, et al. Knowledge, attitude, and satisfaction of patients towards subcutaneous port- a descriptive study J. Evolution Med. Dent. Sci. 2020;9(30):2144-2147, DOI: $10.14260 /$ jemds/2020/467

Submission 28-02-2020,

Peer Review 06-06-2020,

Acceptance 13-06-2020,

Published 27-07-2020.

Copyright (C) 2020 JEMDS. This is an open access article distributed under Creative Commons Attribution License [Attribution 4.0 International (CC BY 4.0)] 


\section{BACKGROUND}

Venous access is common and essential in patients who require repeated infusions. ${ }^{(1)}$ Patients who require repeated blood sampling, repeated blood and intravenous therapy (IV) injections, and chemotherapy are subjected to the stress induced by repeated injections.(2) Sometimes several skin sites are manipulated and used to find the right vein during IV infusions, which exacerbates the stress induced by the underlying disease. Today, direct injection is not recommended for patients who needs repeated infusions.(3) To solve this problem, central venous access devices (CVADs) can be used for a variety of IVs therapies and provide a reliable venous route for long-term or emergency access in the case of emergencies.(4) CVADs are widely used in the specialized wards of hospital, including ICUs or oncology as well as general department such as the emergency department considering their ease of placement and safety.(5) There are different types of CVADs that include catheters inserted through peripheral veins, subcutaneous tunnelled catheters, none tunnelled catheters, and implantable ports.(6) Studies have preferred the use of subcutaneous ports over other methods of obtaining peripheral venous access and consider it as a successful and relatively good CVAD. $(7,8)$ The major advantage of implantable ports over others CVADs is that it is placed under the skin and is thus invisible.(9) Other advantages of these ports include the need for minimal manipulation, less impact on mental body image, reduced incidence of infection, no need for extensive care, no restriction on daily activities, and prolonged durability. ${ }^{(10,11)}$ This method can be used for repeated drug infusions in chemotherapy, blood transfusions, medications, blood sampling, intravenous feeding, and haemodialysis.(12) The use of subcutaneous port system as a method of long-term drug administration is increasing, nowadays.(13) In a study of knowledge and attitude of cancer patients with subcutaneous port, E Johansson et al. (2009) showed poor port-related knowledge among these patients.(14) We found few international articles on patients' knowledge and perception of subcutaneous porta and also found no relevant study in Iran. Considering the advantages of this device for accessing veins, port knowledge plays an important increasing the lifespan, and reducing its complications. Therefore, patients' perception and knowledge of the device and its functioning plays an important role in choosing it. Therefore, the researcher decided to conduct a study to evaluate the knowledge, perception, and satisfaction of patients with subcutaneous port.

\section{METHODS}

The present cross-sectional project was conducted on all patients with subcutaneous port referring to Imam Reza, Ghaem, and Omid Hospitals of Mashhad from January 2018 to March 2019. This study was approved by Mashhad University of Medical Sciences. The STROBE checklist was used to report the study. Research fellows referred to the relevant wards of the hospitals every day and investigated patients with subcutaneous ports for inclusion criteria after expressing research goals and obtaining their informed consent. This study was approved by the ethical committee of Neyshabur
University of Medical Sciences (IR.NUMS.REC.1392.03). Inclusion criteria included wearing subcutaneous ports, repeated drug infusions through the subcutaneous port, being able to speak, write and read, and having consent to participate in the study. The present survey was conducted on all patients with subcutaneous port referring to these hospitals within six months. The instruments used in the present study included questionnaires on perception, knowledge, and satisfaction of patients with subcutaneous port. The content validity and reliability of all instruments were confirmed through Cronbach's alpha test. Then they were completed by the patients with subcutaneous port or otherwise by the researcher in the case of inability of the patient. Data analysis was then carried out using descriptive statistics. Data analysis was carried out using descriptive statistics and mean, standard deviation, relative and absolute frequency distribution in SPSS. SPSS Version 18.0 for Windows (SPSS Inc., Chicago, IL, USA) was used to analyse the data.

\section{RESULTS}

A total of 29 patients (43\%) were female and 36 (57\%) were male. Majority of patients had diploma and most of them were married. Most of the patients were unemployed and had no specific job. Concerning the disease status of the research subjects, the majority of them $(n=27,45 \%)$ had acute myeloid leukemia (AML), the mean frequency of chemotherapy, was $53.9 \pm 6(87 \%)$ of them had caregivers, the majority of them $(\mathrm{n}=34,70 \%)$ referred to the physician as source of information about port care.

\begin{tabular}{|c|c|c|c|}
\hline & $\begin{array}{c}\text { Satisfaction } \\
\text { Results of } \\
\text { the } \\
\text { Majority of } \\
\text { People }\end{array}$ & Frequency & $\%$ \\
\hline $\begin{array}{l}\text { Recommending the use of subcutaneous port to } \\
\text { other similar patients }\end{array}$ & High & 20 & 32.3 \\
\hline $\begin{array}{l}\text { Reselecting the subcutaneous port under } \\
\text { similar conditions }\end{array}$ & High & 24 & 38.7 \\
\hline $\begin{array}{l}\text { The desire to remove the subcutaneous } \\
\text { port as soon as possible }\end{array}$ & Not at all & 28 & 45.9 \\
\hline $\begin{array}{c}\text { Feeling safe and secure with the subcutaneous } \\
\text { port }\end{array}$ & High & 35 & 27 \\
\hline Having a specific port-related issue. & Not at & 34 & 54 \\
\hline Difficulty in everyday activities & Not at all & 40 & 62.5 \\
\hline Suffering from aesthetic problem & Not at all & 28 & 43.1 \\
\hline Fear of inserting the needle into the port & Low & 27 & 41.5 \\
\hline Troublesome monthly port washing process & Not at all & 20 & 30.8 \\
\hline Ability to work & High & 18 & 35.3 \\
\hline $\begin{array}{l}\text { Concerns regarding the incidence of port- } \\
\text { related complications }\end{array}$ & Low & 15 & 24.6 \\
\hline Being regretful regarding the port placement & Not a & 39 & 65 \\
\hline Lack of enjoying life due t & Not a & 39 & 63.9 \\
\hline Having bad feelings regarding catheter insertion & Not at all & 37 & 67.3 \\
\hline $\begin{array}{c}\text { Direct intravenous injection instead of the port } \\
\text { placement }\end{array}$ & Not at all & 35 & 68.6 \\
\hline Painful port placement & Nota & 25 & 44.6 \\
\hline Feeling pain at the port insertion site & Not at all & 30 & 48.4 \\
\hline Itching around the port insertion site & Not at all & 37 & 62.7 \\
\hline Being worry regarding poor port performance. & Low & 24 & 40.3 \\
\hline $\begin{array}{l}\text { Being worry regarding the poor port } \\
\text { performance Being worry regarding a change in } \\
\text { the port location during sleep }\end{array}$ & Low & 25 & 40.5 \\
\hline $\begin{array}{l}\text { Being concerned regarding any injury during } \\
\text { activities }\end{array}$ & Low & 22 & 34.4 \\
\hline $\begin{array}{l}\text { Being concerned regarding being hurt when } \\
\text { bumping against others }\end{array}$ & Not at all & 27 & 42.9 \\
\hline Bathing restrictions & Not at all & 37 & 58.7 \\
\hline Exercise restrictions & Not at all & 32 & 54.2 \\
\hline Restricted arm movement & No & 40 & 63.5 \\
\hline Clothing problems & Not at all & 38 & 62.3 \\
\hline Satisfaction with the costs of port placement & Moderate & 21 & 35 \\
\hline Overall satisfaction & High & 26 & 40.6 \\
\hline
\end{tabular}

Table 1. Knowledge, Attitude and Practice towards Subcutaneous Port 
The port was placed under the clavicle in majority of patients $(n=29,63 \%)$ and positioned in the right side in 58 patients $(92 \%)$. The mean duration of disease was $20 \pm 17$ months, the duration of port use was more than one year in 52 individuals (80\%), and the mean number of ports removed was $3 \pm 2.8$. The majority of ports $(n=23,41.7 \%)$ were implanted due to the need for long-term intravenous treatment. Twenty-eight (67.9\%) patients had port complications and pain was the commonly reported complications (15\%). (table 1).

\section{DISCUSSION}

The results of the present research showed that $46.6 \%(\mathrm{~N}=26)$ of patients were very satisfied with port placement and that they recommend this method to similar patients instead of vein finding procedure, which is consistent with the results of a study by Zhou et al.'s study.(15) Zhou et al. focused on the port placement in the internal jugular vein as guided by ultrasonography as a safe method in patients with breast cancer. Patients referred to the port placement as a safe and secure method.(15)

The result of the present study showed that patient had little concern about poor port performance, a change in its location during sleep,, risk of injury during daily activities, as well as no limitation on wearing clothes, bathing and daily activities, which is consistent with the results of a study by Johnson et al. (2009).(14) They reported that patients with subcutaneous ports has less restriction on wearing clothes. Moreover, patients expressed unpleasant experiences only regarding the catheter for placement process,(6) but they expressed higher satisfaction with subcutaneous ports as it was subcutaneously. Other advantages of this method also include a reduction in patient discomfort during injection, a reduction in costs and frequency of infusions.(16) The use of chemotherapy drugs can cause damage to the walls of peripheral arteries, resulting in problems with access to and use of these arteries. Frequent vein findings and difficulty in accessing the arteries were among major problems reported by these patients.(17) In addition, the durability of this device is greater than that of the temporary catheters, which is accompanied by increasing patient satisfaction.

According to the results of the present study, the majority of patients $(n=35,27 \%)$ referred to the subcutaneous port as a highly safe method and the majority of them $(n=27,41.5 \%)$ expressed little fear of the insertion of the needle into the port, which was consistent with the result of a study by Zhou et al.(15) The results of the present study referred to pain as the most common complications (15\%), which was not consistent with a study by Singh et al., (2010). They reported leakage and infection at the port insertion site as the most common complication.(18) Dehkhoda et al. referred to port failure as the most common complication (15\%), which was not consistent with the results of the present study.(19) Therefore, different complications have been reported in various studies that can be related to the placement procedure, patient care, frequency and cause of port placement. ${ }^{(20,21)}$ The use of venous catheters, especially the port catheter, plays an important role in the care of the health of infants, children, and adults. (22) The use of the subcutaneous port, considering its subcutaneous placement, is preferred to other methods of accessing veins. Patients undergoing chemotherapy who need repeated infusions face major problems that include the need to puncture different veins, gradual thinning of their wall structure on the scene involved structure in them, and eventually vein blockage, which lead to pain, discomfort for the patient as well as cause injury to the peripheral arteries, and new problems for these patients.(23) Previous studies show that ports are widely used to prescribe medication, and given the use of subcutaneous ports for fluid management is increasing rapidly worldwide. Port placement is a cheap and fast treatment that has high therapeutic efficacy and low complications. It also brings more comfort to patients and their companions. A total of 126 patients expressed safety with CVAPD and 9 patients expressed fear of leakage at the port placemen site. Furthermore, $30 \%$ of patients thought the use of poor placement increase rapidly in the hospital setting. After examining the medical procedure, a total of 167 patients $(18 \%)$ reported that surgery has had little or no pain, and generally the ports have been removed after an anticancer treatment. Patients also expressed higher satisfaction with this method. It is important to use venous catheters for the care of patient requiring long-term treatment.(24)

\section{CONCLUSIONS}

Results of the present study indicate the need to pay attention to patients' level of knowledge, attitudes, and satisfaction with regard to cancer related complications. These results can be used in patients with acute and chronic conditions. Oncology patients are candidates for using CVCs in various stages of the disease such as surgery, use of chemotherapy drugs, chronic course of disease, and advanced stages of disease for maintenance treatments.

Financial or Other Competing Interests: None.

\section{REFERENCES}

[1] Andersen BM. Central implanted venous access port. In: Andersen BM, ed. Prevention and control of infections in hospitals. Springer 2019:569-79.

[2] Yu Y, Yoon KA, Kang TW, et al. Therapeutic effect of longinterval repeated intravenous administration of human umbilical cord blood-derived mesenchymal stem cells in DBA/1 mice with collagen-induced arthritis. J Tissue Eng Regen Med 2019;13(7):1134-42.

[3] Wells JR, Gater A, Marshall C, et al. Exploring the impact of infusion frequency in hemophilia a: exit interviews with patients participating in bay 94-9027 extension studies (PROTECT VIII). The Patient-Patient-Centered Outcomes Research 2019;12(6):611-9.

[4] Chambers N, Chen YP. Central venous and arterial access for children. In: Sims C, Weber D, Johnson C, eds. A guide to pediatric anesthesia. Springer 2020:465-74.

[5] Martincich I, Cini K, Lapkin S, et al. Central venous access device complications in patients receiving parenteral nutrition in general ward settings: a retrospective 
analysis. Journal of Parenteral and Enteral Nutrition 2019.

[6] Rajasekhar A, Streiff MB. Etiology and management of upper-extremity catheter-related thrombosis in cancer patients. In: Soff G, ed. Thrombosis and hemostasis in cancer. Springer 2019:117-37.

[7] Tajani A, Au A, Fields JM. Ultrasound-guided central venous access. In: Adhikari S, Blaivas M, eds. The ultimate guide to point-of-care ultrasound-guided procedures. Springer 2020:81-98.

[8] Raptis DA, Neal K, Bhalla S. Imaging approach to misplaced central venous catheters. Radiol Clin North Am 2020;58(1):105-17.

[9] Beck O, Muensterer O, Hofmann S, et al. Central venous access devices (CVAD) in pediatric oncology patients-a single center retrospective study over more than 9 years. Front Pediatr 2019;7:260.

[10] Ryan C, Hesselgreaves $\mathrm{H}, \mathrm{Wu}$ O, et al. Patient acceptability of three different central venous access devices for the delivery of systemic anticancer therapy: a qualitative study. BMJ Open 2019;9(7):e026077.

[11] Bertoglio S, Cafiero F, Meszaros P, et al. PICC-PORT totally implantable vascular access device in breast cancer patients undergoing chemotherapy. J Vascular Access 2019:1129729819884482.

[12] Gomes CMPP, de Araújo MS. Evaluation of long-stay catheter in patients undergoing chemotherapyexperience of the Americas integrated oncology center. European Journal of Surgical Oncology 2020;46(2):e1612.

[13] Taibi A, Bardet MS, Fontanier SD, et al. Managing chemotherapy extravasation in totally implantable central venous access: use of subcutaneous wash-out technique. J Vasc Access 2020:1129729820905174.

[14] Johansson E, Engervall P, Björvell H, et al. Patients' perceptions of having a central venous catheter or a totally implantable subcutaneous port system-results from a randomised study in acute leukaemia. Support Care Cancer 2009;17(2):137-43.
[15] Zhou J, Qian S, He W, et al. Implanting totally implantable venous access port via the internal jugular vein guided by ultrasonography is feasible and safe in patients with breast cancer. World J Surg Oncol 2014;12:378.

[16] Gabriel JA. Catheter lock solutions to prevent CVADrelated infection. Br J Nurs 2020;29(3):S25-9.

[17] Dinçer M, Kocakuşak A, Hut A, et al. Comparison of two different central venous access device insertion techniques: no evil in details. Med Bull Haseki 2019;57:914.

[18] Duwadi S, Zhao Q, Budal BS. Peripherally inserted central catheters in critically ill patients-complications and its prevention: a review. International Journal of Nursing Sciences 2019;6(1):99-105.

[19] Madmoli M, Izadi M, Madmoli M, et al. A systematic review study of the most important complications of chemotherapy in cancer patients. Journal of Biotechnology and Bioengineering. 2019;3(1):2-7.

[20] Hofmann S, Goedeke J, König TT, et al. Multivariate analysis on complications of central venous access devices in children with cancer and severe disease influenced by catheter tip position and vessel insertion site (A STROBE-compliant study). Surg Oncol 2020;34:1723.

[21] Nailon RE, Rupp ME, Lyden E. A Day in the Life of a CVAD. Journal of Infusion Nurs 2019;42(3):125-31.

[22] Sridhar DC, Abou-Ismail MY, Ahuja SP. Central venous catheter-related thrombosis in children and adults. Thromb Res 2020;187:103-112.

[23] Pu YL, Li ZS, Zhi XX, et al. Complications and costs of peripherally inserted central venous catheters compared with implantable port catheters for cancer patients: a meta-analysis. Cancer Nurs 2019.

[24] Lenz H, Myre K, Draegni T, et al. A five-year data report of long-term central venous catheters focusing on early complications. Anesthesiol Res Pract 2019;2019:6769506. 